\title{
O controle na resolução de problemas matemáticos: uma experiência na formação de professores
}

\section{Control en la resolución de problemas matemáticos: una experiencia en formación docente}

\author{
Paulo Gonçalo Farias Gonçalves* \\ ORCID iD 0000-0001-5714-2008 \\ Isauro Beltrán Núñez ${ }^{* *}$ \\ ORCID iD 0000-0003-3224-4694
}

\begin{abstract}
Resumo
Organizar os processos de aprendizagem de maneira independente, consciente e reflexiva, isto é, aprender a aprender, é uma competência essencial para um ser humano do século XXI. Dentre as condições necessárias para isso, o controle na resolução de problemas matemáticos tem sido apontando pelas investigações como um componente pouco explorado no contexto da aprendizagem em Matemática. Diante disso, o presente artigo analisa a influência de uma experiência formativa na reelaboração da orientação da ação de controle na resolução de problemas matemáticos de estudantes de licenciatura. Este estudo foi desenvolvido na Universidade Federal do Cariri, campus Brejo Santo-CE e teve como participantes oito discentes de cursos de licenciatura. Se constituindo como uma pesquisa experiência formativa, os instrumentos utilizados foram: observação, prova pedagógica, diário dos alunos e o questionário. Os dados foram explorados segundo uma análise de conteúdo. Verificamos, por meio de um diagnóstico, que os participantes não possuíam uma compreensão apropriada acerca da ação de controle. A partir da experiência formativa, foi possível observar mudanças na tomada de consciência pelos discentes sobre a relevância da orientação do controle enquanto guia para um melhor entendimento e mitigação dos erros durante o processo de resolução de problemas matemáticos. Os processos de verificação e ajuste que constituem o controle tornam essa habilidade essencial para um indivíduo da sociedade contemporânea. Portanto, é de suma importância que mais investigações sejam desenvolvidas sobre o tema, visando a proliferação de mais práticas educativas que discutam esse componente e contribuam para a formação de aprendizes autônomos.
\end{abstract}

Palavras-chave: Aprendizagem. Teoria de P. Ya. Galperin. Base Orientadora da Ação. Controle. Resolução de Problemas.

\section{Resumen}

Organizar los procesos de aprendizaje de forma independiente, consciente y reflexiva, es decir, aprender a aprender, es una competencia esencial para un ser humano en el siglo XXI. Entre las condiciones necesarias para esto, el control en la resolución de problemas matemáticos ha sido señalado por las investigaciones como un componente poco explorado en el contexto del aprendizaje en Matemáticas. A la luz de esto, el presente artículo analiza la influencia de una experiencia formativa en la reelaboración de la orientación de la acción de control en la resolución de problemas matemáticos de estudiantes de pregrado. Este estudio fue desarrollado en la Universidade Federal do Cariri, campus Brejo Santo-CE y tuvo como participantes ocho estudiantes de cursos de

\footnotetext{
* Doutor em Educação pela Universidade Federal do Rio Grande do Norte (UFRN). Professor Adjunto da Universidade Federal do Cariri (UFCA), Brejo Santo, Ceará, Brasil. E-mail: paulo.goncalo@ufca.edu.br. ** Doutor em Ciências Pedagógicas pela Universidade de Havana (UH). Professor Titular da Universidade Federal do Rio Grande do Norte (UFRN), Natal, Rio Grande do Norte, Brasil. E-mail: isaurobeltran@yahoo.com.br.
} 
pregrado. Al constituirse como una investigación de experiencia formativa, los instrumentos utilizados fueron: observación, prueba pedagógica, diario de los alumnos y cuestionario. Los datos fueron explorados de acuerdo con un análisis de contenido. Verificamos, a través de un diagnóstico, que los participantes no tenían una comprensión adecuada sobre la acción de control. Desde la experiencia formativa, fue posible observar cambios en la conciencia de los estudiantes sobre la relevancia de la orientación de control como una guía para una mejor comprensión y mitigación de errores durante el proceso de resolución de problemas matemáticos. Los procesos de verificación y ajuste que constituyen el control hacen que esta habilidad sea esencial para un individuo en la sociedad contemporánea. Por lo tanto, es de suma importancia que se desarrollen más investigaciones sobre el tema, con el objetivo de la proliferación de más prácticas educativas que discutan este componente y contribuyan a la formación de aprendices autónomos.

Palabras clave: Aprendizaje. Teoría de P. Ya. Galperin. Bases orientadoras para la acción Control. Solución de problemas.

\section{Introdução}

$\mathrm{O}$ atual contexto de acesso facilitado e rápido às informações, por meio de diferentes tecnologias digitais, faz com que um modelo de educação focado no mero acúmulo de conhecimentos seja obsoleto para a formação de um indivíduo da sociedade contemporânea. Assim, saber gerenciar os processos de aprendizagem de maneira independente, consciente e reflexiva, isto é, aprender a aprender, é uma competência exigida para o exercício da cidadania no século XXI.

Dentre as condições que se fazem necessárias para o aprender a aprender, à luz do enfoque histórico-cultural, nos debruçamos sobre o controle da aprendizagem na resolução de problemas matemáticos. Por possibilitar a verificação e a correção da ação, o controle é uma condição necessária para melhoria da prática pedagógica em Matemática (GONÇALVES, 2020).

Conforme Núñez, Melo e Gonçalves (2019, p. 340), o controle propicia ao aprendiz melhorar sua tomada de consciência sobre a aprendizagem, selecionar estratégias adequadas para aprender, avaliar o próprio progresso, aprender com seus erros, entre outros. Assim, ao contribuir com a formação desses aspectos qualitativos, o controle possibilita que o discente assuma maiores responsabilidades sobre sua aprendizagem, contribuindo para aperfeiçoar esses discentes enquanto aprendizes autônomos.

Durante a resolução de problemas matemáticos, em particular, a falta de critérios objetivos adequados, que permitam ao estudante controlar esse processo, pode fazer com que o seja totalmente desconsiderado, ou realizado de forma tênue durante o processo formativo, impossibilitando, dentre outros aspectos, uma melhor compreensão da solução do problema e a mitigação de erros.

Por conta disso, é de suma importância que sejam desenvolvidas práticas pedagógicas 
planejadas para permitir ao discente assumir, paulatinamente, a função de monitorar e ajustar sua própria aprendizagem e, assim, auxiliar na formação de um aprendiz melhor.

Diante do quadro exposto, o presente artigo se constitui como um recorte de Gonçalves (2020) e tem como objetivo analisar a influência de uma experiência formativa na reelaboração da orientação da ação de controle na resolução de problemas matemáticos de estudantes de licenciatura.

\section{A teoria de P. Ya Galperin e a ação de controle}

A teoria de formação planejada das ações mentais e dos conceitos foi elaborada por Piotr Yakovlevich Galperin (1902-1988), a partir de seus estudos sobre a formação das ações mentais, segundo o enfoque histórico-cultural. P. Ya. Galperin constituiu sua teoria como um modelo de explicação do processo de assimilação da ação externa em mental, por etapas, a partir de uma orientação planejada e segundo indicadores qualitativos determinados. Em particular, a referida teoria se debruça sobre o processo de organização da aprendizagem enquanto via para o desenvolvimento intelectual humano.

Para Galperin (2001c, p. 85), a aprendizagem é compreendida como "toda atividade cujo resultado é a formação de novos conhecimentos e habilidades em quem a executa, a incorporação de novas qualidades aos conhecimentos e habilidades que já se possuem". Comungando dessa perspectiva, Núñez e Barros (2019, p. 91) afirmam que ao aprender, o discente "apropria-se de novas ações (ou atualiza as que já domina), as quais lhe permitem a assimilação de novos conhecimentos e, dessa forma, elabora e reestrutura as representações mentais, como orientação, das novas situações/tarefas a serem resolvidas".

Enquanto atividade, a aprendizagem possui como principais momentos funcionais: orientação, execução e controle. A orientação se refere à representação mental que permite planejar, antever e dirigir como a aprendizagem será executada e controlada. Já a execução é o momento em que o processo de aprendizagem é colocado em prática segundo a orientação, sendo ainda um objeto de regulação. Por fim, o controle consiste na verificação da qualidade da execução durante e ao final da atividade e, quando necessário, nos ajustes da execução da aprendizagem e de sua orientação.

Acerca desse último momento funcional, Galperin (1989c) afirma que a ação de controle, no plano mental, consiste na habilidade de ser atento. Segundo o autor, o pensamento forma-se no duo entre seu conteúdo pensável e a ação que direciona os processos mentais do indivíduo para agir sobre esse conteúdo (GALPERIN, 1989a, 1989c). A partir desse 
entendimento, ação mental principal e seu respectivo controle, embora independentes, se assimilam de maneira integrada.

Petrovski (1986, p. 170) define a atenção como um processo cognoscitivo de "inclinação e concentração da psique (consciência) em determinados objetos que supõem uma elevação do nível da atividade". A inclinação se refere à seleção e à manutenção da atenção por certo tempo, de forma voluntária ou não, de quais objetos a atividade do sujeito será direcionada. Por outro lado, a concentração indica o não desvio da atenção e o impedimento que outras atividades concorrentes sejam postas em ação pelo indivíduo.

Por nortear e influenciar na qualidade da execução e do controle, a orientação ocupa um lugar de destaque na teoria de P. Ya. Galperin. O autor justifica essa relevância, afirmando que "a função vital da mente consiste em seu comportamento orientador, baseado na reflexão mental de uma situação problemática" (GALPERIN, 1992, p. 78).

Segundo a teoria de P. Ya. Galperin, a orientação do indivíduo se dá por meio da base orientadora da ação (BOA), que consiste na "representação antecipada da tarefa, assim como o sistema de orientadores, que são necessários para seu cumprimento, formam o plano da futura ação, a base para sua direção" (GALPERIN, 2001b, p. 46). Esse entendimento parte da premissa de que toda a ação humana é precedida por uma base orientadora, determinante para sua qualidade (GALPERIN, 1989a).

No que diz respeito a ação de controle, essa é realizada como parte integrante da BOA. Nesse sentido, ao internalizar a BOA, o indivíduo internaliza também seu controle, que o possibilita ser capaz de lidar de forma independente com a execução do seu ato de aprender, a partir do sistema de condições pré-estabelecido, e monitorar sua aprendizagem, segundo um produto idealizado.

Galperin (2001a) elabora uma tipologia para as BOAs segundo três características principais: generalização, subdividida em particular (orienta uma situação restrita) ou geral (orienta um conjunto de situações); completude, podendo ser completa (quando o sistema de condições necessárias e suficientes é explicitado) ou incompleta (quando o sistema de condições necessárias e suficientes não é totalmente explicitado) e forma de obtenção, sendo ou preparada (dada pronta ao sujeito) ou independente (elaborada pelo próprio sujeito, sob mediação ou não de outro sujeito). A partir de uma combinação das três características supracitadas, as BOAs são nomeadas do tipo I ao tipo VIII.

A partir de suas investigações, Galperin (2001c) aponta que a base orientadora da ação mais promissora, para orientar a atividade de aprendizagem, consiste na BOA geral, completa e independente, chamada de BOA tipo III (ou BOA III). 
Segundo Galperin (1992), a aprendizagem resultante da utilização de uma orientação do tipo III apresenta uma influência relevante no desenvolvimento intelectual dos estudantes, pois é direcionada para apropriação de um método geral do pensamento que possibilita ao aprendiz orientar-se apropriadamente frente a uma situação. Endossando esse entendimento sobre a BOA III, Núñez e Ramalho (2017, p. 10) afirmam que esse tipo de orientação "expressa o que é essencial ao objeto de assimilação em questão (invariante), que permite responder a uma variedade de problemas propostos dentro dos limites da generalização".

Desse modo, ao invés da aprendizagem ser estruturada para o estudo de uma orientação particular para cada tarefa, a BOA III apresenta um conteúdo generalizado, obtido pelos aprendizes (com ou sem a mediação do professor) e com todas as condições necessárias e suficientes para subsidiar a solução de diferentes tarefas agrupáveis sob essa mesma orientação.

Para a organização da atividade de aprendizagem é fundamental que a base orientadora da ação seja inicialmente elaborada e materializada na forma de um esquema, que representa o produto final a ser assimilado pelos discentes. Diante dessa necessidade, Galperin (1989b) apresenta o esquema da base orientadora completa da ação (EBOCA).

O EBOCA pode ser entendido como a representação materializada da base de orientadora da ação desejável para uma determinada ação (GALPERIN, 1989b). Segundo o autor, esse esquema:

[...] incorpora tudo o que um aluno deve 'entender' na tarefa à sua frente, e esse 'entendimento' é expresso pela ação: o aluno sistematicamente (não a esmo!) executa todas as instruções do esquema corretamente nas tarefas, que variam substancialmente. Esse ‘comportamento' indica que o aluno está sendo guiado pelas relações essenciais nas tarefas e que suas ações são racionais (GALPERIN, 1989b, p. $70)$.

Para Núñez e Ramalho (2017, p. 13), o esquema da base orientadora completa da ação "fornece aos estudantes uma ferramenta cultural para a generalização teórica, que permite a compreensão de um conjunto de situações ou de um dado domínio". Por meio do EBOCA, os discentes terão à sua disposição, desde o princípio da atividade de aprendizagem, um guia completo para execução e controle das tarefas.

Um dos formatos que o EBOCA pode adquirir consiste em evidenciar três aspectos inerentes à ação mental que será objeto da atividade de aprendizagem: a definição da ação mental a ser formada (modelo do objeto); o sistema operacional de execução da ação (modelo da ação) e o sistema de operações para controlar a execução da ação (modelo de controle).

No que se refere ao seu processo de elaboração da BOA III (representado de forma materializada como um EBOCA), um dos caminhos é a aplicação do método teórico de análise da atividade, que se inicia com uma análise de diferentes orientações da ação a ser assimilada 
e culmina na identificação dos elementos em comum, invariantes, que constituirão o conteúdo do EBOCA planejado (TALIZINA, 1988).

A partir do levantamento e análise dos invariantes das orientações propostas por autores que discutem a resolução de problemas sob a perspectiva do enfoque histórico-cultural, Gonçalves (2020) elabora o EBOCA da habilidade de resolver problemas matemáticos. O Quadro 1 sintetiza o referido esquema, dividido entre os três modelos (do objeto, da ação e de controle) e subdivididos em ações (A1, A2, A3, A4), operações $(\mathrm{O} 1, \mathrm{O} 2, \ldots, \mathrm{O} 12)$ e operações de controle $(\mathrm{C} 1, \mathrm{C} 2, \ldots, \mathrm{C} 12)$ :

\section{Modelo do Objeto}

Atividade de busca pela solução de uma contradição definida a partir do que é conhecido e desconhecido em uma situação-problema, por meio de conhecimentos matemáticos.

\begin{tabular}{|c|c|}
\hline Modelo da Ação & Modelo de Controle \\
\hline $\begin{array}{l}\text { A1: Analisar a situação-problema. } \\
\text { O1: Ler o enunciado e determinar se corresponde a uma } \\
\text { situação-problema. Caso corresponda, resolver utilizando o } \\
\text { cartão de estudo. Do contrário, procurar outra orientação. } \\
\text { O2: Reconhecer o que é conhecido e o que é desconhecido. } \\
\text { O3: Definir o problema, a partir da contradição entre o } \\
\text { conhecido e o desconhecido. } \\
\text { O4: Representar o problema a partir do que é conhecido, } \\
\text { desconhecido e procurado. }\end{array}$ & $\begin{array}{l}\mathrm{C} 1 \text { : O enunciado trata de uma situação- } \\
\text { problema? } \\
\text { C2: Reconheceu-se o conhecido? Reconheceu- } \\
\text { se o desconhecido? } \\
\text { C3: Definiu-se o problema, a partir do que é } \\
\text { conhecido e desconhecido na situação- } \\
\text { problema? } \\
\text { C4: Foi criado um modelo do problema a ser } \\
\text { resolvido? }\end{array}$ \\
\hline $\begin{array}{l}\text { A2: Planejar uma estratégia para solução do problema. } \\
\text { O5: Determinar as condições para a solução do problema. } \\
\text { O6: Elaborar uma estratégia para resolução, segundo as } \\
\text { condições do problema. }\end{array}$ & $\begin{array}{l}\text { C5: Foram analisadas e determinadas as } \\
\text { condições nas quais se resolverá o problema? } \\
\text { Quais são essas condições? } \\
\text { C6: Por que a estratégia elaborada é apropriada } \\
\text { para solução do problema, segundo as } \\
\text { condições estabelecidas? }\end{array}$ \\
\hline $\begin{array}{l}\text { A3: Executar a estratégia para resolução do problema. } \\
\text { O7: Realizar a resolução do problema de acordo com o } \\
\text { planejado. } \\
\text { O8: Interpretar o resultado encontrado em função do que é } \\
\text { procurado. }\end{array}$ & $\begin{array}{l}\text { C7: A solução do problema se realiza segundo o } \\
\text { planejado, considerando as condições e a } \\
\text { representação do problema? } \\
\text { C8: Chegou-se a uma solução do problema? } \\
\text { Caso positivo, analisou-se a resposta de modo a } \\
\text { justificá-la como resposta ao problema? }\end{array}$ \\
\hline $\begin{array}{l}\text { A4: Avaliar a resolução do problema. } \\
\text { O9: Verificar se a solução do problema está de acordo com } \\
\text { o que é procurado. } \\
\text { O10: Caso a resposta esteja correta, refletir sobre os } \\
\text { aspectos que favoreceram a esse resultado. } \\
\text { O11: Caso a resposta seja negativa, ou não tenha chegado } \\
\text { a uma resposta, refletir e reformular caso seja necessário, o } \\
\text { problema e/ou a estratégia de solução. Corrigir os erros. } \\
\text { O12: Relacionar os resultados obtidos com conhecimentos } \\
\text { anteriores e com novos conhecimentos. }\end{array}$ & $\begin{array}{l}\text { C9: As operações anteriores estão adequadas ao } \\
\text { que é procurado? } \\
\text { C10: Quais aspectos favoreceram ao resultado? } \\
\text { C11: O que é preciso corrigir para solucionar o } \\
\text { problema? } \\
\text { C12: Como os resultados obtidos se relacionam } \\
\text { com elementos já conhecidos e com novos } \\
\text { conhecimentos? }\end{array}$ \\
\hline
\end{tabular}

Quadro 1 - EBOCA da habilidade de resolver problemas matemáticos planejado pelo professor Fonte: Gonçalves (2020, p. 101-102)

O referido EBOCA da habilidade de resolver problemas matemáticos representa um conteúdo desejável (BOA III), a ser assimilado pelo discente. (Re)elaborar de modo 
independente uma orientação geral e completa, no início da atividade de aprendizagem, possibilita ao estudante que não seja preciso haver uma mudança no conteúdo da sua orientação durante esse processo, mas apenas em sua forma, inicialmente material/materializada, passando pela linguagem externa e culminando na forma mental.

Convém destacar que, conforme apresentado no esquema exposto no Quadro 1, ao compor uma mesma orientação, as ações de resolver problemas matemáticos e de controle devem ser assimiladas de forma integrada.

Essas mudanças no formato da ação ocorrem de maneira paulatina, segundo etapas que se distinguem pela forma e pelas características que o indivíduo vai adquirindo durante esse processo (GALPERIN, 2001b).

A teoria de formação planejada das ações mentais e dos conceitos é constituída por cinco etapas, sintetizadas conforme Quadro 2.

\begin{tabular}{|c|l|}
\hline Etapa & \multicolumn{1}{c|}{ Descrição } \\
\hline Motivação inicial & $\begin{array}{l}\text { Preparo e motivação dos discentes para assimilação dos conhecimentos e } \\
\text { habilidades planejadas (NÚNEZ, 2009). }\end{array}$ \\
\hline $\begin{array}{c}\text { (Re)elaboração da base } \\
\text { orientadora da ação } \\
\text { (BOA) }\end{array}$ & $\begin{array}{l}\text { Estabelecimento do plano da ação, no modelo da atividade a ser realizada, que } \\
\text { congrega o conjunto de orientações necessárias e suficientes para realização das } \\
\text { tarefas voltadas para formação das ações mentais e dos conceitos (GALPEIN, } \\
\text { 2001b). }\end{array}$ \\
\hline $\begin{array}{c}\text { Material ou } \\
\text { materializada }\end{array}$ & $\begin{array}{l}\text { Ação direta sobre o objeto (forma material) ou sobre sua representação (forma } \\
\text { materializada). De modo detalhado e, em pares, os sujeitos executam e controlam } \\
\text { todas as operações que compõem a orientação, utilizando apoio do EBOCA. }\end{array}$ \\
\hline Linguagem externa & $\begin{array}{l}\text { Ação representada de forma oral ou escrita. Trabalhando em pares, os sujeitos } \\
\text { continuam a desenvolver a ação detalhada, mas sem utilizar apoio do EBOCA. }\end{array}$ \\
\hline Mental & $\begin{array}{l}\text { Ação abreviada e em processo de automatização no plano mental. Trabalho } \\
\text { independente do discente, sem apoio do EBOCA. }\end{array}$ \\
Quadro 2 - Etapas de assimilação das ações mentais \\
Fonte: elaborado pelos autores
\end{tabular}

É importante destacar que as etapas da teoria de formação planejada das ações mentais e dos conceitos não devem ser compreendidas de modo linear. Segundo Galperin (2001c), percorrer todo o ciclo da teoria só é necessário nos casos em que a ação é nova para o indivíduo. Do contrário, é preciso identificar o nível de formação da habilidade nos estudantes e percorrer somente as etapas pendentes.

Assim como qualquer ação, o controle também pode ser assimilado por meio das etapas propostas pela teoria de formação planejada das ações mentais e dos conceitos.

Após um momento preliminar, que auxilie o estudante a convergir seus motivos para aprender sobre o controle com os objetivos propostos na atividade (motivação inicial), reelabora-se o entendimento da ação a ser formada, seu aspecto operacional e critérios de controle (reelaboração da BOA). 
A seguir, a ação de controle é aplicada em diferentes tarefas que estejam dentro dos limites de generalização da orientação. Inicialmente, é realizada seguindo detalhadamente a orientação contida no EBOCA, e em duplas, alternando-se entre as funções de resolver o problema e controlar a resolução do colega (material/materializada).

$\mathrm{Na}$ etapa seguinte (linguagem externa), o controle é feito com auxílio de um colega. Nessa etapa, o modelo de controle da BOA está em vias de internalização. Por isso, os discentes já não resolvem as tarefas com o suporte do EBOCA.

Por fim (etapa mental), o controle é realizado sem apoio do EBOCA e individualmente. Nesse momento, essa ação já se consolida no plano interno, ou seja, se configura como ato da atenção voluntária, que se dá de forma menos detalhada e automatizada.

Ao assimilar uma ação segundo as etapas propostas pela teoria de P. Ya. Galperin, o sujeito da atividade adquire novas características, em função dos objetivos previamente definidos no início da organização da atividade de aprendizagem. Essas características da ação são também nomeadas de indicadores qualitativos da ação. Detalhamos, no Quadro 3, cada uma das características da ação.

\begin{tabular}{|c|l|}
\hline $\begin{array}{c}\text { Indicador } \\
\text { qualitativo }\end{array}$ & \multicolumn{1}{c|}{ Descrição } \\
\hline Forma da ação & $\begin{array}{c}\text { Consiste no plano (material ou materializado, linguagem externa, mental) em que a ação está } \\
\text { sendo desenvolvida. }\end{array}$ \\
\hline $\begin{array}{c}\text { Grau de } \\
\text { generalização }\end{array}$ & $\begin{array}{l}\text { Refere-se à capacidade dos indivíduos de aplicação do conceito ou habilidade apreendida } \\
\text { em situações dentro dos limites desses conhecimentos. }\end{array}$ \\
\hline $\begin{array}{c}\text { Grau de } \\
\text { detalhamento }\end{array}$ & $\begin{array}{l}\text { É a capacidade de detalhamento dos elementos estruturais da ação apreendida pelos } \\
\text { indivíduos. }\end{array}$ \\
\hline $\begin{array}{c}\text { Grau de } \\
\text { consciência }\end{array}$ & $\begin{array}{l}\text { Está relacionada a capacidade do indivíduo de aplicar corretamente o conceito ou habilidade } \\
\text { apreendida e fundamentar, verbalmente, os procedimentos que executou. }\end{array}$ \\
\hline $\begin{array}{c}\text { Grau de } \\
\text { independência }\end{array}$ & Tem relação com a capacidade do estudante de executar (ou não) a ação, sem auxílio. \\
\hline Grau de solidez & $\begin{array}{l}\text { Consiste na capacidade do indivíduo de executar a ação apreendida após algum tempo em } \\
\text { que foi formada. }\end{array}$ \\
\hline Grau de domínio & Refere-se ao processo de automatização da ação. \\
\hline Caráter racional & Apresenta as condições necessárias para realização da ação pelo discente. \\
\hline
\end{tabular}

Quadro 3 - Indicadores qualitativos da ação

Fonte: adaptado de Talizina (2009, p. 179)

O conjunto de características da ação supracitadas são essenciais para a atividade de aprendizagem, visto que funcionam como indicativos da qualidade do processo de assimilação do objeto estudado, tanto para quem aprende, quanto para quem ensina. 
Em particular, os indicadores qualitativos possibilitam ao docente definir previamente, junto com os objetivos do processo de ensino, quais características quer que seu discente adquira após a assimilação da ação; assim como caracterizar e aferir, qualitativamente, os indicadores dos sujeitos relativos a determinado conteúdo antes, durante ou após a experiência formativa.

As características da ação, juntamente com a orientação e as etapas de formação, compõem o sistema explicativo de assimilação das ações mentais e dos conceitos proposto na teoria de P. Ya. Galperin. Findada essa discussão, apresentamos, na seção seguinte, o percurso metodológico adotado na pesquisa.

\section{Metodologia}

A presente pesquisa foi desenvolvida com oito alunos matriculados na disciplina Laboratório de Educação Matemática I, ofertada no Instituto de Formação de Educadores, campus da Universidade Federal do Cariri na cidade de Brejo Santo-CE. A proposta do estudo foi apresentada aos estudantes antes do início da investigação e a adesão entre os alunos da disciplina foi voluntária e unânime.

Foi empreendida uma pesquisa do tipo experiência formativa (EF). A EF é um método de investigação utilizado no âmbito do enfoque histórico-cultural e tem como intuito investigar, a partir da organização e aplicação de um conjunto de atividades de aprendizagem, em quais condições se dá a formação adequada de novos conhecimentos e habilidades nos estudantes.

Conforme Davídov (1988, p. 196), a EF “pressupõe a projeção e modelação do conteúdo de novas formações mentais a serem constituídas, dos meios psicológicos e pedagógicos e das vias de sua formação".

A experiência formativa, enquanto forma de desenvolvimento das atividades para a reelaboração, pelos estudantes, da ação de que eles dispõem para controlar, foi desenvolvida em função de quatro momentos principais. São eles: elaboração da EF, que englobou o planejamento da orientação desejada, materializada no EBOCA elaborado pelo professor (Quadro 1), do diagnóstico inicial do nível de compreensão dos estudantes acerca da ação de controle na resolução de problemas matemáticos, das tarefas, formadas por situaçõesproblemas de matemática, e dos instrumentos de pesquisa; aplicação do diagnóstico inicial; desenvolvimento da EF, estruturada em função de etapas propostas pela teoria de P. Ya. Galperin; a avaliação da EF.

No que se refere aos instrumentos de pesquisa, foram empregados: a prova pedagógica, 
a observação, o diário dos alunos e o questionário. Os referidos recursos são descritos no Quadro 4:

\begin{tabular}{|c|c|c|}
\hline $\begin{array}{c}\text { Instrumento de } \\
\text { pesquisa }\end{array}$ & Descrição & Momento da EF \\
\hline Prova pedagógica & $\begin{array}{l}\text { Conjunto de questões conceituais e/ou de aplicação para } \\
\text { caracterização do nível de compreensão dos estudantes acerca da } \\
\text { ação a ser diagnosticada. }\end{array}$ & $\begin{array}{l}\text { Diagnóstico } \\
\text { inicial }\end{array}$ \\
\hline Observação & $\begin{array}{l}\text { Utilização dos sentidos do pesquisador (visão, audição etc.), } \\
\text { direcionados pelo objeto de estudo, para apreensão dos } \\
\text { acontecimentos relevantes da investigação. }\end{array}$ & Desenvolvimento \\
\hline Diário dos alunos & $\begin{array}{l}\text { Rol de anotações relatando acontecimentos, impressões, } \\
\text { dificuldades etc., acerca de situações vivenciadas pelos discentes. }\end{array}$ & \\
\hline Questionário & $\begin{array}{l}\text { Conjunto de perguntas para caracterização da percepção dos } \\
\text { discentes sobre as experiências vivenciadas durante a investigação. }\end{array}$ & Avaliação da EF \\
\hline
\end{tabular}

Quadro 4 - Instrumentos de pesquisa utilizados

Fonte: elaborado pelos autores

O procedimento de análise usado para tratamento dos dados coletados foi a análise de conteúdo (BARDIN, 1977, p. 42), que congrega diferentes estratégias de "análise das comunicações visando obter, por procedimentos, sistemáticos e objetivos de descrição do conteúdo das mensagens, indicadores (quantitativos ou não) que permitam a inferência de conhecimentos relativos às condições de produção/recepção (variáveis inferidas) destas mensagens".

Partindo de uma pré-análise, foi realizada a organização e leitura preliminar dos dados coletados para definição de elementos balizadores para interpretação. Em seguida, ocorreu a exploração do material para uma primeira redução das informações coletadas em função de categorias emergentes. Por fim, seguiu-se para o tratamento dos resultados, a inferência e a interpretação, que contemplou a sistematização dos dados, a partir da atribuição de significados para os dados em função das categorias propostas e do arcabouço teórico adotado.

\section{Resultados e discussões}

A execução da experiência formativa teve como enfoque favorecer o processo de reelaboração da orientação da ação de controle na resolução de problemas matemáticos de estudantes de licenciatura.

Visando melhor organizar as discussões sobre como se deu essa intervenção, os resultados e discussões são apresentados em função de momentos da experiência formativa: diagnóstico inicial, desenvolvimento da experiência formativa e avaliação da experiência formativa.

O momento de diagnóstico inicial teve duração de 2 horas e seu intuito foi caracterizar 
a compreensão da ação de controle na resolução de problemas matemáticos dos participantes da experiência formativa. A referência utilizada para análise da orientação dos estudantes foi o esquema da base orientadora completa da ação (EBOCA) elaborado pelo professor (Quadro 1).

A fim de caracterizar a compreensão dos discentes sobre a habilidade em questão, a prova pedagógica indagou os discentes acerca do que é (modelo do objeto), como resolver problemas matemáticos (modelo da ação) e como controlar esse processo (modelo e controle).

Reunindo os resultados obtidos no diagnóstico inicial da orientação dos alunos, segundo o percentual de elementos corretos, apresentamos a Tabela 1:

Tabela 1 - Percentual de adequação das orientações iniciais dos alunos em relação ao EBOCA

\begin{tabular}{cccc}
\hline Participante & $\begin{array}{c}\text { Modelo do } \\
\text { Objeto }\end{array}$ & $\begin{array}{c}\text { Modelo da } \\
\text { Ação }\end{array}$ & $\begin{array}{c}\text { Modelo de } \\
\text { Controle }\end{array}$ \\
P1 & $25 \%$ & $33,3 \%$ & $0 \%$ \\
P2 & $25 \%$ & $33,3 \%$ & $0 \%$ \\
P3 & $50 \%$ & $16,7 \%$ & $0 \%$ \\
P4 & $0 \%$ & $8,3 \%$ & $0 \%$ \\
P5 & $0 \%$ & $33,3 \%$ & $0 \%$ \\
P6 & $0 \%$ & $41,7 \%$ & $0 \%$ \\
P7 & $25 \%$ & $25 \%$ & $0 \%$ \\
P8 & $50 \%$ & $25 \%$ & $0 \%$ \\
\hline \multicolumn{4}{r}{}
\end{tabular}

É possível notar que não há uma correlação entre a compreensão dos estudantes sobre o que é resolver problemas matemáticos (modelo do objeto), como resolver problemas matemáticos (modelo da ação) e sobre o como controlar o processo de resolução de problemas matemáticos (modelo de controle).

Em particular, nenhum dos alunos evidencia, no diagnóstico inicial, ter consciência sobre a realização da ação controle na resolução de problemas matemáticos. Esse fato endossa a afirmação de que a habilidade de controle na resolução de problemas matemáticos dos alunos é pouco desenvolvida, considerando o nível de escolaridade em que eles se situam.

Assim, o processo de diagnóstico inicial forneceu indícios da compreensão dos discentes acerca do processo de resolução de problemas matemáticos, possibilitando que a experiência formativa seja realizada segundo os princípios da provável zona de desenvolvimento próximo de cada estudante, assim como preconiza Vygotsky (1995).

Em relação ao desenvolvimento da EF, esse momento englobou: motivação inicial (2h), reelaboração da orientação dos alunos (4h) e o controle da solução de tarefas (8h).

A motivação inicial se deu por meio da apresentação de uma situação-problema e pela explanação e discussão sobre a ação de controle na resolução de problemas e sua relevância para a aprendizagem, à luz da teoria de P. Ya. Galperin. Toda a discussão em sala de aula partiu 
das respostas dadas pelos discentes durante a prova pedagógica, ressaltando as convergências e divergências entre os diferentes entendimentos apresentados.

Por conta da discrepância entre as orientações dos alunos, diagnosticadas anteriormente, e a orientação adotada como referência, planejada pelo professor, na etapa de (re)elaboração da BOA de resolver problemas matemáticos dos discente, o processo de favorecimento de uma reelaboração inicial da orientação dos alunos foi dividido em duas partes: uma primeira reelaboração da orientação, em duplas, após apresentação de alguns fundamentos teóricos para subsidiar esse processo; uma segunda reelaboração realizada em conjunto com a turma. Em ambos os casos, as negociações de sentidos e significados tiveram a mediação do professor.

Após o final da reelaboração da orientação em duplas, comparamos a convergência dessas primeiras adequações das orientações com a orientação de referência elaborado pelo professor (Quadro 1) e sintetizamos o percentual de convergência na Tabela 2.

Tabela 2 - Percentual de adequação das orientações reelaboradas em duplas em relação a orientação do professor

\begin{tabular}{cccc}
\hline Participante & Modelo do Objeto & Modelo da Ação & Modelo de Controle \\
P1 & $75 \%$ & $50 \%$ & $45,8 \%$ \\
P2 & $75 \%$ & $50 \%$ & $45,8 \%$ \\
P3 & $50 \%$ & $33,3 \%$ & $37,5 \%$ \\
P4 & $75 \%$ & $50 \%$ & $45,8 \%$ \\
P5 & $50 \%$ & $50 \%$ & $45,8 \%$ \\
P6 & $25 \%$ & $37,5 \%$ & $12,5 \%$ \\
P7 & $75 \%$ & $50 \%$ & $29,2 \%$ \\
P8 & $50 \%$ & $50 \%$ & $29,2 \%$ \\
\hline
\end{tabular}

Fonte: elaborada pelos autores

É possível notar que o modelo do objeto é o elemento da orientação dos alunos que mais se aproxima da orientação de referência elaborada pelo professor, seguido do modelo da ação e do modelo de controle.

Comparando os dados sobre a orientação da ação de controle na resolução de problemas caracterizada no diagnóstico inicial (Quadro 5), e após sua primeira reelaboração em duplas (Tabela 2), segundo seus respectivos modelos do objeto (MO), modelo da ação (MA) e modelo de controle MC), temos os seguintes resultados sintetizados na Figura 1: 


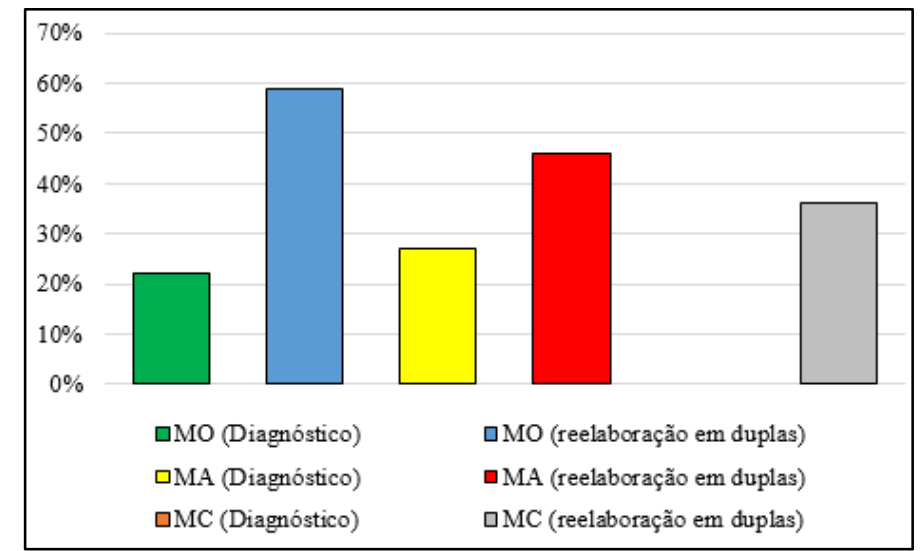

Figura 1 - Comparativo entre diagnóstico inicial e reelaboração da orientação em duplas Fonte: elaborada pelos autores

De modo geral, verificamos um aumento percentual em todos os modelos que constituem a ação de controle na resolução de problemas, o que pode indicar uma melhoria na compreensão da turma sobre essa ação.

Na segunda parte da reelaboração da orientação dos alunos para construção do esquema da base orientadora completa da ação (EBOCA) da turma, foram retomados os tópicos da aula anterior, mas agora focados no trabalho conjunto entre todos os participantes, realizado a partir da mediação do professor. Nesse momento, a negociação de sentidos e significados para reelaboração da orientação dos discentes culminou na aproximação dessa com a orientação planejada pelo professor (Quadro 1).

Na etapa de realização do controle da solução de tarefas, os discentes tiveram o apoio do EBOCA (Quadro 1) e, em duplas, alternavam-se entre resolver e controlar as situaçõesproblemas propostas. Para cada tarefa, enquanto um aluno resolvia, o outro auxiliava-o, controlando todo o processo com o suporte do EBOCA. Ambos os membros das duplas deveriam registrar suas ações.

Debruçando-se sobre a ação de controle na solução das seis tarefas propostas durante a experiência formativa, divididas em primeiro bloco (tarefas 1, 2 e 3 ) e segundo bloco (tarefas 4, 5 e 6), classificamos as respostas dos discentes em duas categorias, a saber: descrição genérica das operações de controle (DG) e descrições específicas das operações de controle (DE). 
A categoria DG diz respeito aos tipos de respostas que se restringiram a transcrever versões do modelo de controle de forma ampla, de modo que seria possível encaixá-las em qualquer outra resposta. Um exemplo de resposta classificada nessa categoria é apresentado na Figura 2.

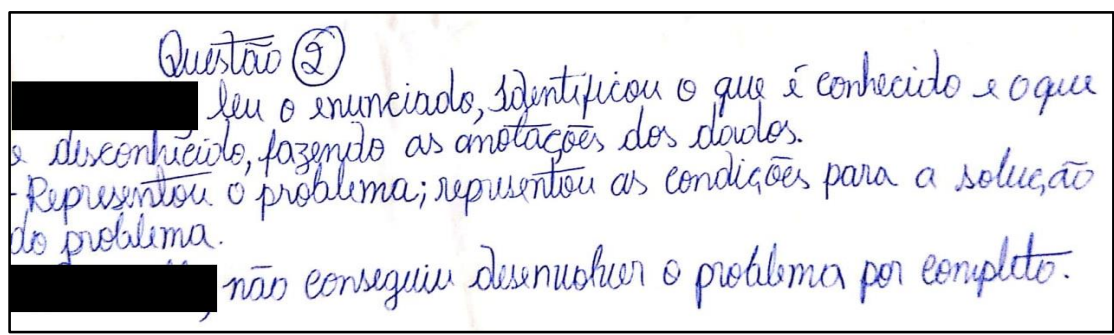

Figura 2 - Descrição da ação de controle classificada como DG Fonte: acervo dos autores

Por outro lado, a categoria DE reúne as descrições que apresentaram maiores detalhamentos das ações de controle na tarefa em tela, assim como exemplificado na Figura 3:

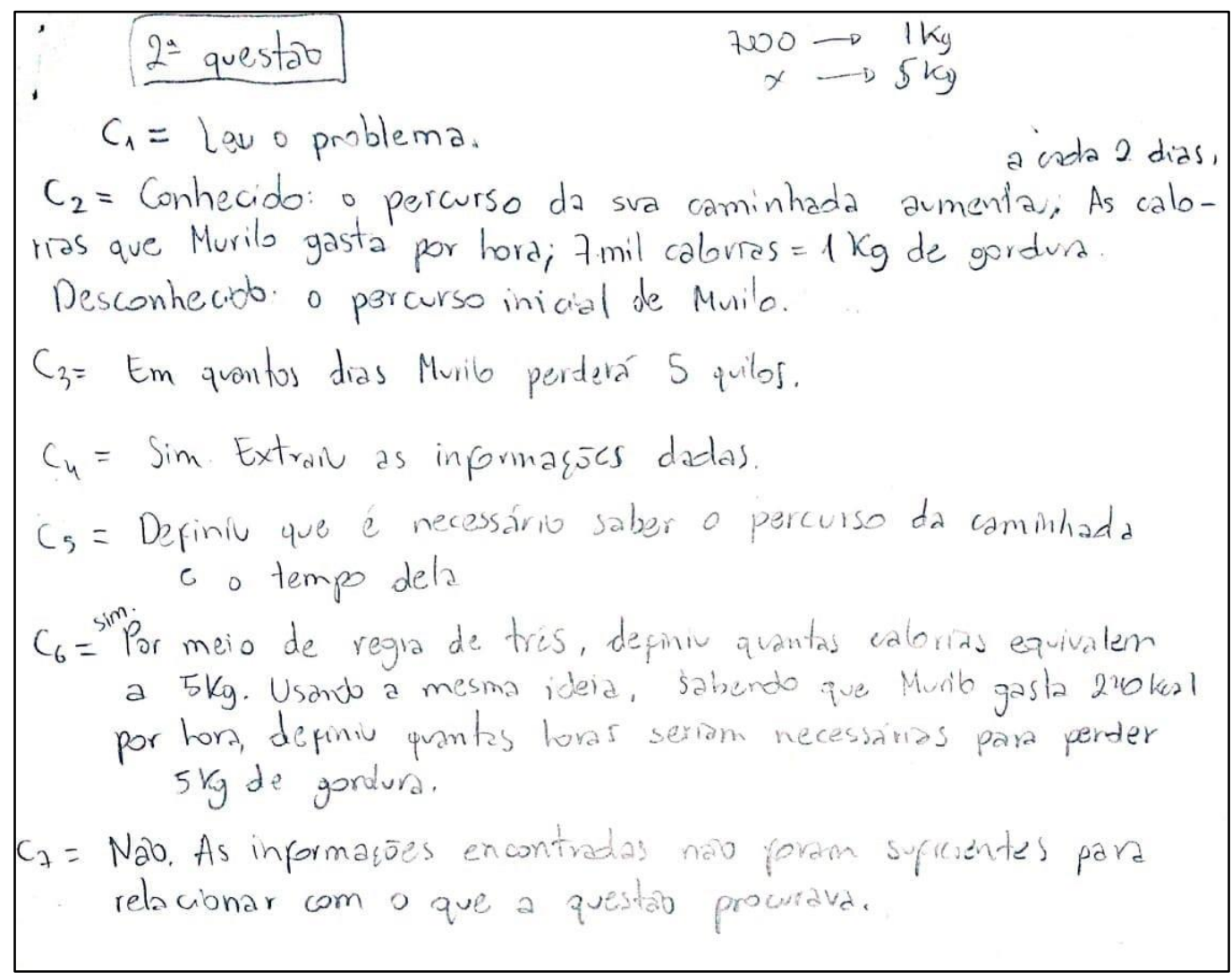

Figura 3 - Descrição da ação de controle classificada como DE Fonte: acervo dos autores

Comparando o primeiro e o segundo bloco de tarefas, houve um decréscimo relativo às respostas gerais (DG) de 66,7\% para 33,3\%, acompanhado de um aumento nas descrições específicas (DE) para a ação de controle, de 33,3\% para 66,7\%. Esse fato sugere uma melhoria no grau de detalhamento da ação de controle na resolução de problemas matemáticos, considerado como um dos indicadores qualitativos da formação de uma ação mental segundo a 
teoria de P. Ya. Galperin (TALIZINA, 2009; NÚÑEZ, 2009). Embora não tenha sido nosso enfoque a formação da ação mental, o resultado evidencia que, mesmo nas primeiras etapas de reelaboração da orientação dos alunos, já se inicia o desenvolvimento de algumas características da ação pelo aprendiz.

Passando a descrever e discutir se houve um favorecimento desse momento da experiência formativa para a reelaboração da orientação dos discentes acerca da ação de controle na resolução de problemas matemáticos, consultamos o diário dos estudantes relativo ao primeiro e ao segundo bloco de tarefas.

De maneira geral, verificamos que $62,5 \%$ dos participantes evidenciaram, em suas anotações, um favorecimento na reelaboração da orientação da ação de controle na resolução de problemas, $25 \%$ das repostas foram inconclusivas, enquanto que $12,5 \%$ relatam que não houve favorecimento. Apresentamos, no Quadro 5 respostas representativas relacionadas a cada uma das categorias mencionadas.

\begin{tabular}{|c|c|c|c|}
\hline Categoria & Participante & Tarefas 1,2 e 3 & Tarefas 4, 5 e 6 \\
\hline $\begin{array}{c}\text { Indicam } \\
\text { favorecimento }\end{array}$ & P3 & $\begin{array}{l}\text { É um pouco complicado você como } \\
\text { controlador pois fica confuso } \\
\text { distinguir com as ações do resolvedor, } \\
\text { de fato a gente fica com vontade de } \\
\text { tomar a ação do colega, o que torna } \\
\text { difícil na ação de controlador. }\end{array}$ & $\begin{array}{l}\text { Como controlador senti menos } \\
\text { dificuldades do que a aula } \\
\text { anterior, isso deve ao fato de está } \\
\text { me adaptando ao EBOCA, } \\
\text { contudo nesse processo que pra } \\
\text { mim é novidade. Defato ajudei em } \\
\text { algumas momentos e até clareei } \\
\text { algumas ideias do resolvedor (em } \\
\text { algumas etapas). }\end{array}$ \\
\hline Inconclusivas & P4 & $\begin{array}{l}\text { O controle no ato da resolução é de } \\
\text { grande relevância, pois existem alguns } \\
\text { erros no desenvolver das questões, } \\
\text { controlar a colega foi uma ótima } \\
\text { experiência. As dificuldades } \\
\text { encontradas foram justamente a } \\
\text { preocupação em estar atrapalhando a } \\
\text { colega, pois a todo momento está } \\
\text { fazendo perguntas relacionadas ao } \\
\text { controle. }\end{array}$ & $\begin{array}{l}\text { Fiz o controle de duas questões. } O \\
\text { controle é uma atividade muito } \\
\text { importante se realizada no } \\
\text { momento certo, pois muitas vezes } \\
\text { meu colega estava resolvendo o } \\
\text { problema e eu quando fazia as } \\
\text { perguntas o atrapalhava. }\end{array}$ \\
\hline $\begin{array}{l}\text { Não indicam } \\
\text { favorecimento }\end{array}$ & P7 & $\begin{array}{l}\text { Ao controlar a resolução do problema } \\
\text { realizado pelo meu colega, percebi que } \\
\text { muitas vezes atrapalhava o seu } \\
\text { raciocínio, e muitas vezes se tornava } \\
\text { difícil acompanhá-lo, pois muitas } \\
\text { ações já eram intuitivas. }\end{array}$ & $\begin{array}{l}\text { Ao realizar o controle, percebi } \\
\text { que muitas vezes atrapalhava o } \\
\text { meu colega, pois, às vezes, ele } \\
\text { estava já em outra operação e eu } \\
\text { o interrompia, fazendo com que } \\
\text { lhe faltasse o raciocínio. }\end{array}$ \\
\hline
\end{tabular}

Quadro 5 - Trechos dos diários dos alunos que exemplificam tipos de respostas encontradas Fonte: elaborado pelos autores

Considerando as respostas de maior recorrência, exemplificadas pelo relato do participante $\mathrm{P} 3$, verificamos que há indícios que houve melhorias na compreensão dos participantes em relação as ações de controle na resolução de problemas matemáticos entre a maioria dos discentes. 
Contudo, ainda houve discentes que externalizaram relatos inconclusivos (participante P4) ou ainda que evidenciaram a prevalência de dificuldades (como, por exemplo, atrapalhar o colega de dupla durante a solução das tarefas), mesmo após as últimas tarefas, o que indicou que não houve melhorias na compreensão da ação de controle.

O momento final, de avaliação da experiência formativa, realizada por meio de um questionário, trouxe dos participantes da pesquisa suas opiniões sobre o que foi vivenciado para suas formações profissionais. Apresentamos, a seguir, um recorte de dados que evidenciaram a relevância do uso do EBOCA e as dificuldades dos discentes durante a experiência formativa.

$\mathrm{O}$ primeiro item indagou se os discentes consideraram o EBOCA importante, no contexto da experiência formativa. De maneira geral, os alunos foram unânimes em afirmar que sim. Especificamente, as respostas puderam ser classificadas em duas categorias, são elas: contribuições do EBOCA para a resolução de problemas (50\%); mudanças de postura dos discentes frente aos problemas $(50 \%)$.

Em relação as contribuições do EBOCA para a resolução de problemas, as respostas dos alunos estão apresentadas no Quadro 6.

\begin{tabular}{|c|c|}
\hline $\begin{array}{c}\text { Contribuições do } \\
\text { EBOCA }\end{array}$ & Exemplos de respostas dos discentes \\
\hline $\begin{array}{l}\text { - Evitar o esquecimento } \\
\text { de etapas e informações; } \\
\text { - Selecionar dados. }\end{array}$ & $\begin{array}{l}\text { Sim. O EBOCA permitiu controlar as ações na resolução de problemas } \\
\text { matemáticos. Esse controle, geralmente fazia mentalmente porém, ao materializá- } \\
\text { lo foi possivel evitar o esquecimento de algumas etapas e informações importantes, } \\
\text { verificando-as e anotando-as, eliminando, ou não utilizando as que não eram tão } \\
\text { importantes para as questões, evitando assim, em algumas situações, me confundir } \\
\text { com as informações dadas no enunciado, desde o que se pedia (o que se procura) } \\
\text { até as que não me interessavam. A construção "personalizada" do EBOCA foi } \\
\text { muito importante (modelo da ação e controle da ação) (Participante P1). }\end{array}$ \\
\hline $\begin{array}{l}\text { - Análise das condições } \\
\text { do problema } \\
\text { - Verificação } \\
\text { - Autocorreção }\end{array}$ & $\begin{array}{l}\text { Relativamente sim; Digo isso, quando estivermos tratando de problemas um pouco } \\
\text { mais complicados, necessariamente nessas situações o controle é importante, } \\
\text { principalmente no que diz respeito às condiçôes do problema e à verificação, uma } \\
\text { vez que podemos nos autocorrigir (Participante P3). }\end{array}$ \\
\hline Mitigar erros & $\begin{array}{l}\text { Sim, o EBOCA foi importante para a resolução de situações-problemas, pois com } \\
\text { o auxílio do mesmo foi possível minimizar os erros durante o processo de resolução } \\
\text { (Participante P4). }\end{array}$ \\
\hline $\begin{array}{l}\text { Conhecimento } \\
\text { profissional do professor }\end{array}$ & $\begin{array}{l}\text { Foi de bastante importância pois com ele vimos a aprender coisas que sejam } \\
\text { importantes para nossa carreira. Com ela vai andar muito na hora de resolver } \\
\text { problemas que aparecer (Participante P6). }\end{array}$ \\
\hline
\end{tabular}

Quadro 6 - Contribuições do EBOCA na perspectiva dos discentes Fonte: elaborado pelos autores

Percebemos que todas as respostas evidenciaram aspectos distintos relativos ao uso da orientação reelaborada e materializada no esquema da base orientadora completa da ação, tanto de caráter mais geral (como suas contribuições para o conhecimento profissional do professor, por exemplo), quanto para outros mais específicos (minimizar erros, por exemplo). 
O segundo tópico apresentado nesse recorte da avaliação da experiência formativa solicitou que os alunos destacassem até três dificuldades que apresentaram durante o processo de aprendizagem da orientação da ação de controle na resolução de problemas matemáticos.

A dificuldade de maior recorrência foi relacionada ao modelo de controle, com 29,2\%. Os entraves relatados pelos discentes foram associados à confusão, utilização, registro e avaliação do controle.

Confundir, aplicar ou interpretar o modelo da ação foi o que causou dificuldades em $20,8 \%$ dos participantes. Logo a seguir, $16,7 \%$ das respostas mencionaram dificuldades no processo de elaboração do esquema da base orientadora completa da ação (EBOCA) ou, ainda, na adaptação do discente para seguir essa orientação esquematizada.

O trabalho em duplas para solução das tarefas por meio da orientação materializada foi apontado como dificuldade em 12,5\% das respostas. Especificamente, os alunos relataram dificuldades entre quem resolve e quem controla a resolução do problema, em intervir no processo um do outro sem se atrapalhar ou, ainda, de compreender a explicação dada pelo colega.

Outras dificuldades de menor recorrência apontadas foram: na compreensão das etapas $(8,3 \%)$, no tempo para resolução do problema $(8,3 \%)$ e em verificar as condições do problema, sobretudo em problemas sem solução ou de múltiplas soluções $(4,2 \%)$.

\section{Considerações finais}

A formação de um aprendiz autônomo, capaz de lidar com o amplo conjunto de informações disponíveis para um indivíduo do mundo contemporâneo, tem sido um dos desafios para a educação.

Embora o controle da resolução de problemas matemáticos seja uma das condições necessárias para o aprender a aprender na perspectiva do enfoque histórico-cultural, as pesquisas sobre o tema têm apontado deficiências na formação de professores, tanto na utilização dessa habilidade durante os processos de aprendizagem dos licenciandos, quanto nas práticas docentes desses profissionais em sala de aula.

Considerando esse quadro, este artigo consiste em um recorte de uma pesquisa doutoral que estudou a influência na reelaboração da orientação da ação de controle da resolução de problemas matemáticos, por meio uma experiência formativa fundamentada na teoria de P. Ya. Galperin. 
No que se refere ao diagnóstico do nível de desenvolvimento inicial dos participantes da pesquisa acerca da orientação da ação de controle da resolução de problemas matemáticos, o fato de se ter encontrado baixos níveis de convergências com a orientação planejada pelo professor (quase $22 \%$ em relação ao modelo do objeto, $27 \%$ no modelo da ação e $0 \%$ com o modelo de controle), sugere que os licenciandos participantes da experiência formativa não possuíam uma compreensão apropriada, sobretudo, relacionada à ação de controle.

Desse modo, a presente investigação endossa um quadro já apontado por outras pesquisas sobre o tema e reforça a necessidade de um maior esforço no campo educacional para proposição de práticas educativas focadas em promover melhorias nas ações mentais dos discentes, necessárias para o aprender a aprender.

Sobre a avaliação dos participantes acerca da experiência formativa, diante dos relatos desses discentes em relação à tomada de consciência sobre a relevância da orientação enquanto guia para um melhor entendimento e mitigação dos erros durante o processo de resolução de problemas matemáticos, tivemos indícios de que, na perspectiva dos alunos, a participação na presente investigação favoreceu na reelaboração da compreensão do controle.

Dentre as limitações da pesquisa, destacamos, inicialmente, o fato de a experiência formativa que propusemos não ter sido voltada para a formação de uma habilidade, mas apenas para influir na reelaboração de sua orientação. Por conta disso, as atividades que empreendemos não perpassaram todas as etapas necessárias para formação das ações mentais propostas por P. Ya. Galperin, chegando apenas até a etapa materializada. Além disso, os indicadores qualitativos da ação não foram utilizados.

A investigação empreendida abre possibilidades para o surgimento de novas pesquisas que se debrucem sobre a temática em tela. A realização de estudos longitudinais que se proponham a empreender a formação da habilidade de controle da aprendizagem, no âmbito de diferentes níveis de ensino, torna-se promissora para um maior aprofundamento das condições sobre as quais o controle é assimilado pelo indivíduo.

Os processos de verificação e ajuste da ação humana que constituem o controle tornam essa habilidade cognoscitiva um componente importante da personalidade de um indivíduo do século XXI. Portanto, é de suma importância que mais investigações sejam desenvolvidas sobre o tema, visando a proliferação de mais práticas educativas que discutam esse componente e contribuam para a formação de aprendizes autônomos.

\section{Referências}

BARDIN, L. Análise de conteúdo. Tradução de Luís Antero Reto e Augusto Pinheiro. Lisboa: 
Edições 70, 1977.

DAVÍDOV, V. V. La enseñanza escolar y el desarrollo psíquico: Investigación psicológica teórica y experimental. Moscú: Editorial Progreso, 1988.

GALPERIN, P. Y. Mental actions as a basis for the formation of thoughts and images. Soviet Psychology, v. 27, n. 3, p. 45-64, 1989a.

GALPERIN, P. Y. Organization of mental activity and the effectiveness of learning. Soviet Psychology, v. 27, n. 3, p. 65-82, 1989b.

GALPERIN, P. Y. The problem of attention. Soviet Psychology, v. 27, n. 3, p. 83-92, 1989c.

GALPERIN, P. Y. Stage-by-Stage formation as a method of psychological investigation. Journal of Russian and East European Psychology, v. 4, n. 30, p. 60-80, 1992.

GALPERIN, P. Y. Tipos de orientación y tipos de formación de las acciones y de los conceptos. In: QUINTANAR, L. R. (org.). La formación de las funciones psicológicas durante el desarrollo del niño. Tlaxcala: Universidad Autónoma de Tlaxcala, 2001a. p. 41-44.

GALPERIN, P. Y. Sobre la formación de los conceptos y de las acciones mentales. In: QUINTANAR, L. R. (org.). La formación de las funciones psicológicas durante el desarrollo del niño. Tlaxcala: Universidad Autónoma de Tlaxcala, 2001b. p. 45-56.

GALPERIN, P. Y. La dirección del processo de aprendizaje. In: QUINTANAR, L. R. (org.). La formacion de las funciones psicológicas durante el desarrollo del niño. Tlaxcala: Universidad Autónoma de Tlaxcala, 2001c. p. 85-92.

GONÇALVES, P. G. F. A orientação da ação de controle na resolução de problemas matemáticos em professores: uma experiência formativa à luz da Teoria de P. Ya. Galperin. 2020. 205f. Tese (Doutorado em Educação) - Universidade Federal do Rio Grande do Norte, Natal, 2020.

NÚÑEZ, I. B. Vygosky, Leontiev e Galperin: formação de conceitos e princípios didáticos. Brasília: Liber Livro, 2009.

NÚÑEZ, I. B.; BARROS, S. C. B de. O conhecimento de professores sobre a orientação do estudante na aprendizagem. Cadernos de Pesquisa, São Luís, v. 26, n. 2, p. 87-105, abr.jun. 2019.

NÚÑEZ, I. B.; MELO, M. M. P.; GONÇALVES, P. G. F. Controle e autorregulação da aprendizagem na teoria de P. Ya. Galperin. Linhas Críticas, Brasília, v. 24, p. 322-341, 2019.

NÚÑEZ, I. B.; RAMALHO, B. L. A teoria da Formação Planejada das Ações Mentais e dos Conceitos de P. Ya. Galperin: contribuições para a Didática Desenvolvimental. Obutchénie, Uberlândia, v. 1, n. 1, p. 70-97, jan./abr. 2017.

PETROVSKI, A. Psicologia general: manual didáctico para los institutos de pedagogía. 3. ed. Moscú: Editorial Progreso, 1986.

TALIZINA, N. F. Psicologia de la enseñanza. Traduzido por Ana Clavijo. Moscú: Editorial Progreso, 1988.

TALIZINA, N. F. La teoría de la actividad aplicada a la enseñanza. Traduzido por Yulia Solovieva e Luis Quintanar Rojas. Puebla: Benemérita Universidad Autónoma de Puebla, 2009.

VYGOTSKY, L. S. Obras escogidas III (incluye problemas del desarrollo de la psique). Traduzido 
por Lydiaa Kuper. Madrid: Visor, 1995. Tomo III.

Submetido em 28 de Maio de 2020. Aprovado em 13 de Setembro de 2020. 